\title{
Indicadores de cambios climáticos en el desierto
}

\section{Indicators of climate change in the desert}

\author{
Jaime Deza ${ }^{1}$
}

\section{RESUMEN}

Los trabajos de ubicación y estudio de sitios arqueológicos en las quebradas y orillas de ríos secos en la costa peruana, norte y centro en especial, que se viene realizando desde la década de los años setenta del siglo pasado, demuestran una asociación de tales sitios con la existencia de relictos de bosques desaparecidos, que señalarían ambientes diferentes a los actuales, en los que el hombre ha desarrollado su cultura Los restos más antigüos se encuentran ubicados en las cuencas que se ubican a seis - diez kilómetros de distancia del litoral actual, ya en ríos de corto recorrido o afluentes de los ríos actuales, en cuyas márgenes se registran restos de cazadores con diez mil años de antigüedad; pero también en cuencas que se ubican a veinte kilómetros del litoral en las que se identifica, arquitectura planificada con antigüedad de cinco mil años antes del presente.

Estos datos nos estarían indicando un avance de la línea de lluvias hacia las estribaciones andinas actuales, y el nacimiento o expansión de las pampas desérticas costeñas con una posible cronología que nos permitiría conocer las características paleoclimáticas de la región, e inclusive establecer comparaciones o correlacionarlas con otras. El estudio tiene como objetivo general, identificar en el espacio y el tiempo la presencia humana y su relación de la orografía con esta hipótesis climática en el desierto de Guayaquil, margen izquierda del valle Zaña, como una contribución de indicadores para el estudio de los cambios climáticos en la costa norte peruana.

Palabras clave: Paleoclima, paleolítico, talleres líticos, Andes Centrales, petroglifos, panandinos.

\section{ABSTRACT}

The job location and the archaeological sites study located in the ravines and banks of dry rivers in the Peruvian coast, north and in particular in the center. Which has been done since the seventies decade of the last century have shown that there is an association between these remainders and the existence of relict in the disappeared forests, that would indicate different environments than today where man has developed its culture.

The oldest remains are located in basins that are situated six to ten kilometers away from the current coast, and in short haul rivers or current tributaries of the rivers, whose margins remains of hunters with ten thousand years antiquity are registered; but also in basins that are located twenty kilometers from the coast where it is identified, planned with age of five thousand years before the present architecture.

This data would indicate a preview of the rainwater line into the current Andean foothills, and the beginning or expansion of the desert coastal pampas with a possible timeline that would allow us to know the paleoclimatic characteristics of the region, and even comparisons and correlate them with other. 
The study's general objective is to identify in space and time human presence and its relation to the topography with this climatic hypothesis at the desert Guayaquil, left bank of the Zana Valley, as a contribution of indicators for the study of climate change on the northern coast Peruvian.

Keywords: Palaeoclimate, lithic workshops, Central Andes, petroglyphs, pan-andean.

\section{INTRODUCCIÓN}

Los cambios ambientales en los Andes han condicionado la conducta de los pobladores de manera más intensa de lo que estamos suponiendo, y éstos continúan imperceptibles; pero el desconocimiento de la geografía como una ciencia sistémica, nos ha hecho creer que el escenario es inamovible y en consecuencia no hemos tomado las precauciones convenientes.

Una prueba de ello es el evento de El Niño. Hasta hace algunos años se afirmaba que "se llama así a la corriente de agua marina caliente que aparece a fines del mes de diciembre en el norte peruano" por lo que los pescadores paiteños le llamaban "el niño".

Las fuertes lluvias de los años 1925, 1940, 1956, 1965, 1973, 1983 y 1998 se consideraron "fenómenos", pero con el avance de los medios de monitoreo ya se registra como un evento y se observa su recorrido por el Océano Pacífico afectando a todo el orbe.

En el caso de la costa norte peruana abundan los nombres de quebradas y ríos secos, suponiendo que obedecerían a una formación "antidiluviana", hasta que las lluvias de 1983 y 1998 (Deza 2000/ 2001) en especial, demostraron que estos cauces secos tienen vida y traen caudal, y en consecuencia el trazo de la carretera Panamericana que se construyó rellenando tales desniveles, tuvo que reconstruirse en largos tramos y hacer puentes y badenes. Increíble de aquello hace solamente dieciocho años.

Se entiende entonces que El Niño/Oscilación Sur (ENSO), no es un fenómeno, sino un evento que tiene un ritmo, como todo los sucesos de la naturaleza y que las cuencas secas con sus cauces en la costa peruana, forman parte de un sistema hidrográfico, con periodos oscilantes, cuyos picos se manifiestan en lluvias torrenciales y sequías; y en consecuencia estos ríos secos y quebradas son los canales naturales de desagüe de los años con lluvias intensas (Deza 2001). De ellos tenemos registrados desde Tumbes a Tacna 152 ríos secos y sus quebradas afluentes (Ob. Cit.).

Los trabajos de ubicación y estudio de sitios arqueológicos en las quebradas y orillas de ríos secos en la costa peruana, norte y centro en especial, que venimos realizando desde la década de los años setenta del siglo pasado, nos demuestran una asociación de tales sitios con la existencia de relictos de bosques desaparecidos, ríos, cauces y cuencas que señalarían ambientes diferentes a los actuales en los que el hombre ha desarrollado su cultura (Deza,1991, 2000, 2001, 2006)

Los restos más antiguos los encontramos en las cuencas que se ubican a seis - diez kilómetros de distancia del litoral actual (Deza, 1972), ya en ríos de corto recorrido o afluentes de los ríos actuales, en cuyas márgenes se registran restos de cazadores con diez mil años de antigüedad; pero también en cuencas que se ubican a veinte kilómetros del litoral en las que se identifica, arquitectura planificada con antigüedad de cinco mil años antes del presente (Deza 2008).

Con estas experiencias empíricas planteamos desde entonces como hipótesis, que tales datos nos estarían indicando un avance de la línea de lluvias hacia las estribaciones andinas actuales, y el nacimiento o expansión de las pampas desérticas costeñas, con una posible cronología que nos 
permitiría conocer las características paleo climáticas de la región, e inclusive establecer comparaciones o correlacionarlas con otras.

Uno de los lugares que siguiendo esta perspectiva de hipótesis ha sido explorado y estudiado por nosotros, es el pequeño desierto de Guayaquil, ubicado en la margen izquierda del valle Zaña, distrito de Cayaltí, Chiclayo, región Lambayeque.

El estudio tiene como objetivo general: Identificar en el espacio y el tiempo la presencia humana en el sector, como una contribución de indicadores para el estudio de los cambios climáticos en la costa norte peruana a través del tiempo.

La hipótesis que resulta del lugar "Los sitios arqueológicos ubicados en las márgenes de tres ríos que conforman las cuencas secas, en el desierto de Guayaquil, serían indicadores de una cronología de cambios ambientales en la costa norte del Perú."

\section{Variables de estudio:}

.Orografía actual

.Relictos

.Ubicación y características de los sitios

.Arquitectura

.Cronología relativa

\section{MÉTODOS Y MATERIALES}

El método general de estudio es el de exploración de superficie con una guía de observación directa y el comparativo. Los pasos en el proceso son:

a. Exploración de superficie en cuadrículas de 100 metros por lado (1 Ha) y registro en coordenadas UTM de los sitios identificados.

b. Estudios orográficos de los sitios donde se ubican restos arqueológicos

c. Registro de sitios con información arquitectónica.

d. Análisis de sitios que aporten información cronológica. e. Levantamiento topográfico del lugar y sitios identificados.

\section{f. Levantamiento en 3D de monumentos.}

g. Fotografía.

h. Comparaciones con lugares arqueológicos estudiados en la región.

i.Informes y publicaciones.

\section{RESULTADOS}

En los años de experiencia estudiando los desiertos peruanos, no hemos visto un espacio con tanta información en apenas seis kilómetros cuadrados (600 hectáreas) y una altitud que varía entre 120 y 130 metros.

El río Zaña tiene como característica una fuerte pendiente $(8,17 \%$ en el Alto Zaña, 6,18\% Medio Alto y Medio 0,69\%) (A.L.d A.Z. 2010:7) con una serie de afluentes temporales (enero - marzo) que cuando las lluvias caen en la región yunga y primeras estribaciones andinas, llevan sus aguas por una serie de quebradas colectoras de gran amplitud, y durante los eventos de El Niño / Oscilacion Sur inundan poblaciones.

Pues bien en este sector de estudio (desierto Guayaquil) se observan tres colectores que daban sus aguas en el río Zaña que a decir de la profundidad y amplitud de su cauce, mayor de cien metros, han tenido caudal y es posible que durante algunas épocas éste haya sido constante.

En él hemos registrado diez sitios arqueológicos relacionados directamente a los cauces secos, además de cementerios y campos de cultivo con claras huellas geológicas de inundaciones periódicas. Sitios que ofrecen, en líneas generales, una cronología tentativa que indica que hace diez mil, cinco mil y tres mil años tuvieron una importante ocupación humana. 
Se registra once sitios muy definidos:

\section{Sitio, talleres líticos.}

Ubicación: S $06^{\circ} 55 \quad 5,42^{\prime \prime}$ W $\quad 079^{\circ} 30 \quad 1,26^{\prime \prime}$ y 121 de altitud.

En la falda oriental del cerro registramos un taller con escasas lascas y fragmentos de riolita con inconfundibles huellas de percusión, que pertenecen a la cultura Paiján, cuya cronología se registra en diez mil años antes del presente.

\section{El templo a la boa.}

Ubicación: UTM S $06^{\circ} 55$ 31,01" W $078^{\circ} 28$ 29,39 "

Uno de los ríos secos se forma en las faldas del cerro Las Culebras, en cuyas orillas se encuentra un edificio compuesto de cuatro terrazas artificiales, continuas, de clara factura precerámica, con cuatro figuras hechas con piedras estriadas de $0,15 \mathrm{~m}-0,20 \mathrm{~m}$ promedio, formando espirales de tres metros de diámetro que culminan en una piedra mayor de $0,40 \mathrm{~m}$.

Alegorías, que por sus características se referirían a la boa (es una propuesta de hierofanía), figuras que además se repiten en diversas lomas del sector.

Tal presunción se esgrime por la similitud con las figuras de la culebra que se observan en los petroglifos pre chavín en la región (Deza 2011) y que se asocia además a monolitos hallados en el área con figuras de boas entrelazadas.

\section{Talleres de superficie con lascas}

Ubicación:

Taller 1: S $06^{\circ} 56018^{\prime \prime} \mathrm{W} 079^{\circ} 28$ 693"

Taller 2: S $06^{\circ} 56560^{\prime \prime} \mathrm{W} 079^{\circ} 28201^{\prime \prime}$

A trescientos metros del edificio, siguiendo la orilla derecha del cauce seco, con dirección noroeste, se registran dos talleres de $3 \mathrm{~m}^{2}$.

Por las características del material lítico se trata de restos de talla a percusión y en consecuencia parecería tener una cronología similar al edificio. Es decir utensilios domésticos que pertenecen a los pobladores que construyeron el edificio.

\section{Dos construcciones rectangulares de piedra. Ubicación: S $06^{\circ} 56$ 378” W $079^{\circ} 28$ 269"}

Sitio cerro "El Aguila". Posibles viviendas a la orilla derecha del río seco, de 10 por 6 y 0,70 metros de alto, de piedra estriada sin pegamento, no se registra cerámica. Tiene posible asociación con el edificio principal y a los talleres líticos

\section{Petroglifos.}

Ubicación S $06^{\circ} 56$ 729” W $079^{\circ} 28$ 009”.

En el cono de deyección de una segunda cuenca seca de la que nace un río seco de cauce muy amplio, superior a los cien metros de ancho, se registra una piedra de granodiorita de siete metros de largo en la que se han dibujado figuras que caracterizan a la iconografía anterior a la cultura chavín en el lugar y una de la cultura chavín.

\section{La piedra de cinco huecos.}

Ubicación: S $06^{\circ} 55$ 852" W $079^{\circ} 29$ 661".

Con dirección norte en la falda del cerro se registra una piedra solicitaría de dos metros por lado, de plano cuadrado con cinco hoyos cónicos de $0,30 \mathrm{~m}$ de diámetro.

\section{Piedra con boa en plano relieve en una quebra- da. \\ Ubicación: S $06^{\circ} 55$ 9,55” W $079^{\circ} 301,71 ” 176$ m.s.n.m}

Continuando por las faldas del cerro, en una pequeña quebrada se registran dos piedras con figuras de dos boas entrelazadas por la cabeza, resaltadas aprovechando los estratos naturales de la piedra. Se estima coetánea al edificio.

\section{Escultura en alto relieve de dos boas entrelaza- das, en una roca de $1,40 \mathrm{~m}$ de largo \\ Ubicación: S $06^{\circ} 55 \quad 7,96^{\prime \prime}$ W $079^{\circ} 30$ 2,84" y 121 de altitud.}


Monolito en el que se ha tallado en alto relieve la figura de dos boas entrelazadas por la cabeza y que debería ser el tótem más importante de los pobladores del lugar.

A 30 metros de distancia con dirección noreste se registra otra piedra con la talla en alto relieve de la misma figura iconográfica pero más pequeña, sepultada. Se observa en la parte externa un metro de largo por ochenta centímetros de alto.

\section{Sitio Las Tinajas.}

Ubicación: S $06^{\circ} 55$ 797” W 079³0 142”

Le denominan así los pobladores del lugar por tratarse de dos piedras planas unidas, como una sola plataforma de ocho metros de largo por cuatro metros de ancho, en la cual la mitad es ocupada por once hoyos de hasta $0,30 \mathrm{~m}$ de diámetro, y la otra mitad es plana y está asociada a ocho petroglifos de la cultura chavín.

\section{Huaca La Ternera.}

Ubicación: S $06^{\circ} 55$ 23.18” W 079²9 05.50" 112 alt.

Edificio de barro construido con adobes denticulares. Tiene 25 metros de altura y se ubica al centro del desierto actual, de clara construcción chavín.

\section{El canal de Saltrapón.}

Luego miles de años después vendrían otros pobladores que no se estacionaron en el lugar, fueron campesinos lambayeques, a decir de la cerámica que se registra en superficie, que trazaron por el lugar el canal que viene de Nanchoc y se dirige a Saltrapón en la pampa de Mocupe, con un recorrido estimado de 80 kilómetros (Deza 2006:99).

\section{DISCUSIÓN}

Creemos que este edificio formaría parte de los orígenes de la arquitectura en la región, pues tiene medidas que se repiten en sus terrazas de
83 metros por lado, ángulos rectos, dos plantas con nueve gradas de acceso, construido con una concepción final del edificio, sin reacomodos ni ampliaciones, como contrariamente se observan en construcciones funcionales que se han ido acoplando a la planta original en otros edificios contemporáneos.

Este edificio de $10000 \mathrm{~m}^{2}$, tiene un estimado de 30 $000 \mathrm{~m}^{3}$ de material, lo que demandó una intensa mano de obra para su construcción, y se conserva sin disturbar, limpio, por haber quedado abandonado. Abandono que tal vez se explicaría por una sequía prolongada, como ha ocurrido con otros edificios hace cinco mil años en la costa, como con Illescas (Cárdenas 1978 T1:16), Queneto (Larco 1948:16), Chao (Cárdenas T2: 13), Haldas (Engels 1970:12), Paraíso (Engels 1967) y otros.

Además del edificio que en sus cuatro plataformas encontramos figuras trazadas con piedras estriadas de espirales de tres metros de diámetro; por el hecho de observar en la falda del cerro cuatro piedras de un metro y medio de largo con imágenes de dos boas entrelazadas por las cabezas, en plano y alto relieve, dando la impresión que una estaría devorando a la otra; $y$ por último otra figura de forma zigzageante, recordando el desplazamiento de la boa, de $30 \mathrm{~m}$ de largo, hecha con piedras estriadas, que se une a la plataforma con petroglifos y hoyos cónicos, nos hace suponer que es la representación del dios totémico del pueblo que habitó en lo que ahora es un desierto.

La existencia de boas en el lugar no es novedad. Existen documentos de ello y el más temprano con nueve mil años en excavaciones en Nanchoc (Dillehay 1992). Además de informantes que nos describen sus experiencias y del pueblo de Carahuasi, que en quechua significa ambiente o lugar donde viven culebras grandes.

Todo ello nos orienta a pensar que los habitantes del lugar tendrían por tótem principal a la boa constrictor, no de otra manera entenderíamos la constante representación de la figura. 
El año 1998 la Universidad Alas Peruanas inició el estudio en la margen izquierda de la cuenca del río Zaña, centrándonos en el área que corresponde al distrito de Bolívar, sorprendidos por los relictos de flora de esta microrregión, tan similar a la Rupa Rupa o selva alta amazónica (Deza 1998). Tal afirmación se basaba en los registros de plantas y animales como la chonta (Bactris gasipaes), el sajino (Pecari tajacu), oso de anteojos (Tremarctos ornatus), boas (Boa constrictror) de hasta seis metros, venados (Odoicoleus virginianus) que aún se registra en el poblado de Carahuasi.

La cuenca nace a consecuencia de un farallón de 200 metros de altura que se forma en el lugar y corre hacia el norte con el que chocan las nubes que vienen del valle, formándose una capa de inversión, y de una cascada que forma el afluente que los lugareños la conocen como la "Chorrera del Mandínguez".

Lo más sorprendente es la presencia de conjuntos de petroglifos con hoyos cónicos perfectamente labrados, lizos, tallados en piedras planas, horizontales, asociados a petroglifos chavín, (Deza 2011).

En ese contexto el desierto de Guayaquil es el extremo marginal izquierdo del valle que se cubre de vegetación en épocas de lluvias intensas, por consiguiente la cronología señalada es relativa,la sustentamos por asociación y comparación de las técnicas de construcción, instrumentos líticos y ausencia de cerámica en los sitios arqueológicos más tempranos.

La cronología repetiría los tres momentos de cambios ambientales en la costa que hicieron propicia la estadía del poblador.

\section{CONCLUSIONES}

Los sitios arqueológicos se asientan en los tres cauces secos, afluentes por la margen izquierda del río Zaña, con cronología paleolítica, precerámica, Chavín y Lambayeque.
En consecuencia, sin considerar la escasa muestra lítica del cazador paijanense, dada la magnitud de la obra edificada y los sitios asociados, el lugar debió tener una intensa vegetación que hizo propicia la presencia de una importante población de economía autárquica y recolectora, hace cinco mil años.

Una siguiente ocupación debió realizarse dos mil años después, cuyo centro principal de culto y administrativo se encuentra en el edificio "La Ternera" de 25 metros de alto construido con adobe cónico al centro del actual desierto y en el sitio de Tinajas.

Finalmente agricultores que no habitaron en el lugar construyeron un canal que pasa bordeando las faldas de los cerros del lugar, siguiendo la pendiente natural y que forma parte de un canal que riega las pampas costaneras, abiertas, frente al litoral, a la izquierda del valle y que viene de Nanchoc hacia Saltrapón en las pampas de Mocupe - Lagunas.

Canal fue por asociacion a cerámica Lambayeque en superficie tendria relación.

\section{REFERENCIAS BIBLIOGRÁFICAS}

Administración Local de Agua Zaña

2010 Evaluación de Recursos hídricos, cuenca del río Zaña. MINAGRI. Lambayeque, Perú

\section{Cárdenas Martin, Mercedes}

1978 Columna estratigráfica para los valles de Piura, Chao, Santa, Huaura y Lurín. Tomos I - V Pontificia Universidad Católica del Perú. SAIRAPUC, Lima

Deza Rivasplata, Jaime

1972 Talleres Líticos de Cupisnique. Paijan. Tesis Lcdo. Univerisdad Nacional de Trujillo.

1991 El apogeo de las lanzas, Edición A.P.A lima

2001 ¿Se seca la costa?. Fondo Editorial de la Universidad Alas Peruanas. Lima.

2006 El agua de los Incas Fondo Editorial de la Universidad Alas Peruanas. Lima

2008 Los dioses de la economía, Fondo Editorial UAP. 
2011 La infancia de la palabra escrita. Nuevos descubrimientos en el valle Zaña. Fondo Editorial de la Universidad Alas Peruanas. Lima

2016 El apogeo de las lanzas. Fondo Editorial de la Universidad Alas Peruanas. Lima

Deza Rivasplata, Jaime; Ramírez Prado, Fidel

1998 La quebrada del Mandínguez. Fondo Editorial de la Universidad Alas Peruanas. Lima

2000 Cuando los desiertos eran bosques. Fondo Editorial de la Universidad Alas Peruanas. Lima.

Deza, Jaime; Tacsa, Oscar; Arana, Fernando.

1990 Hacia una investigacion arqueológica en áreas desérticas del litoral peruano: Desierto de Chepen y Zaña. Asociación peruana de arqueolgía. CONCYTEC.

Dillehay,J; Rossen,J;Natherly,P

1992 Ocupación del precerámico medio en la zona alta del valle de Zaña: Innovación o aculturación. En estudios de Arqueología Peruanas. Bonavía editor. Pags. 69 - 82.FONCIENCIAS. Lima

Dollfus, Oliver.

1964 Cambios climáticos en los andes peruanos, Boletín de la Sociedad Geográfica de Lima, Tomo.40-41. Lima

Engel, Frederic

1970 Las lomas de Iguanil y el complejo de Haldas. CIZA. UNALM. Lima

1967 El Compleo ParaÍso en el valle Chillón. Rev. Anales Científicos. UNALM Vol. Nº 3-4. Lima

Larco Hoyle, Rafael

1948 Cronología arqueológica de la costa norte del Perú.

IFEA, Lima 


\section{LEYENDAS DE LAS FOTOGRAFÍAS}



Figura 1 Vista satelital del área mirando al río Zaña, al fondo cañaverales de Cayaltí. 


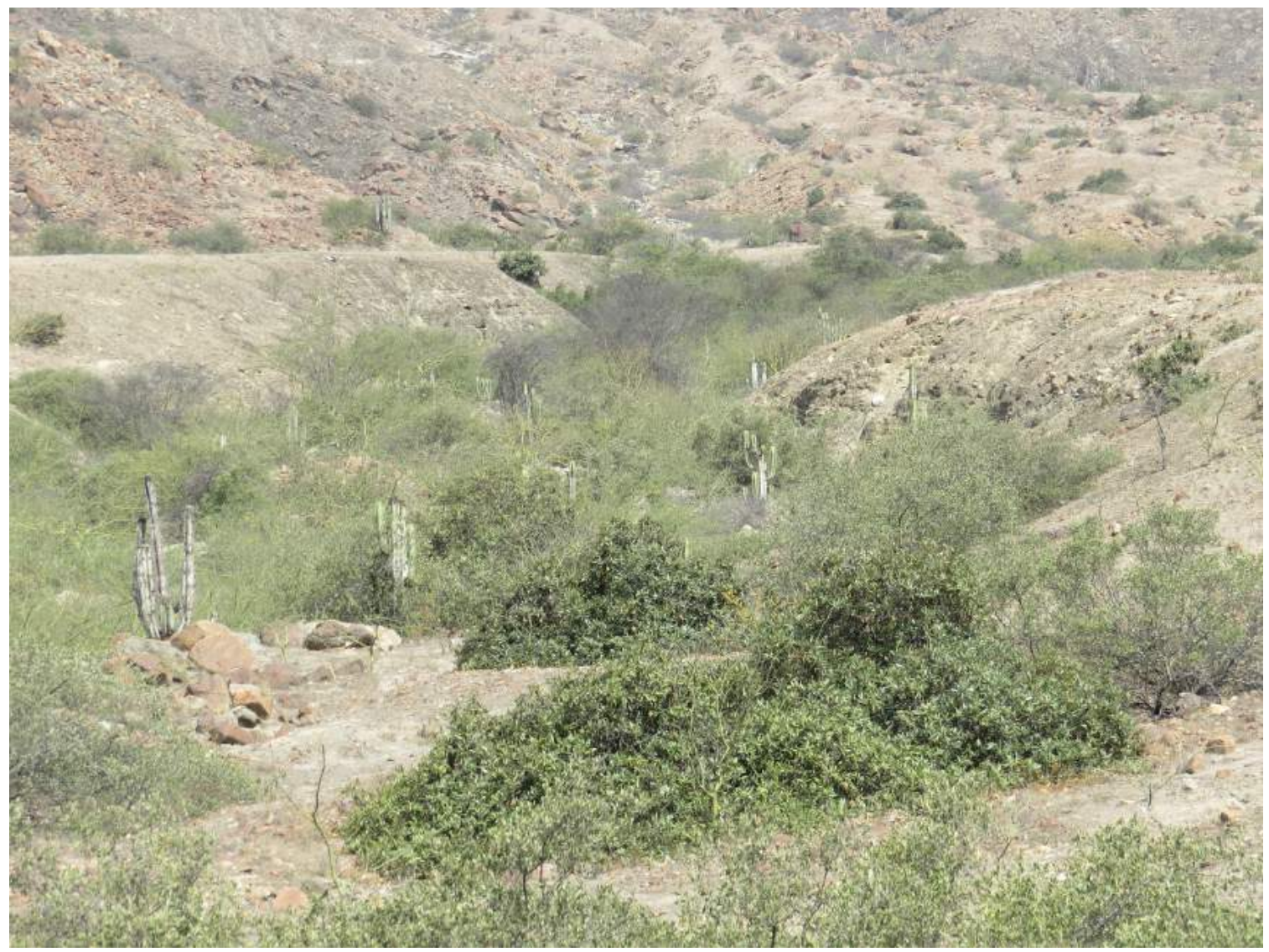

Figura 2 Relicto. Puquio en el desierto de Guayaquil, cercano al Templo de la Boa.

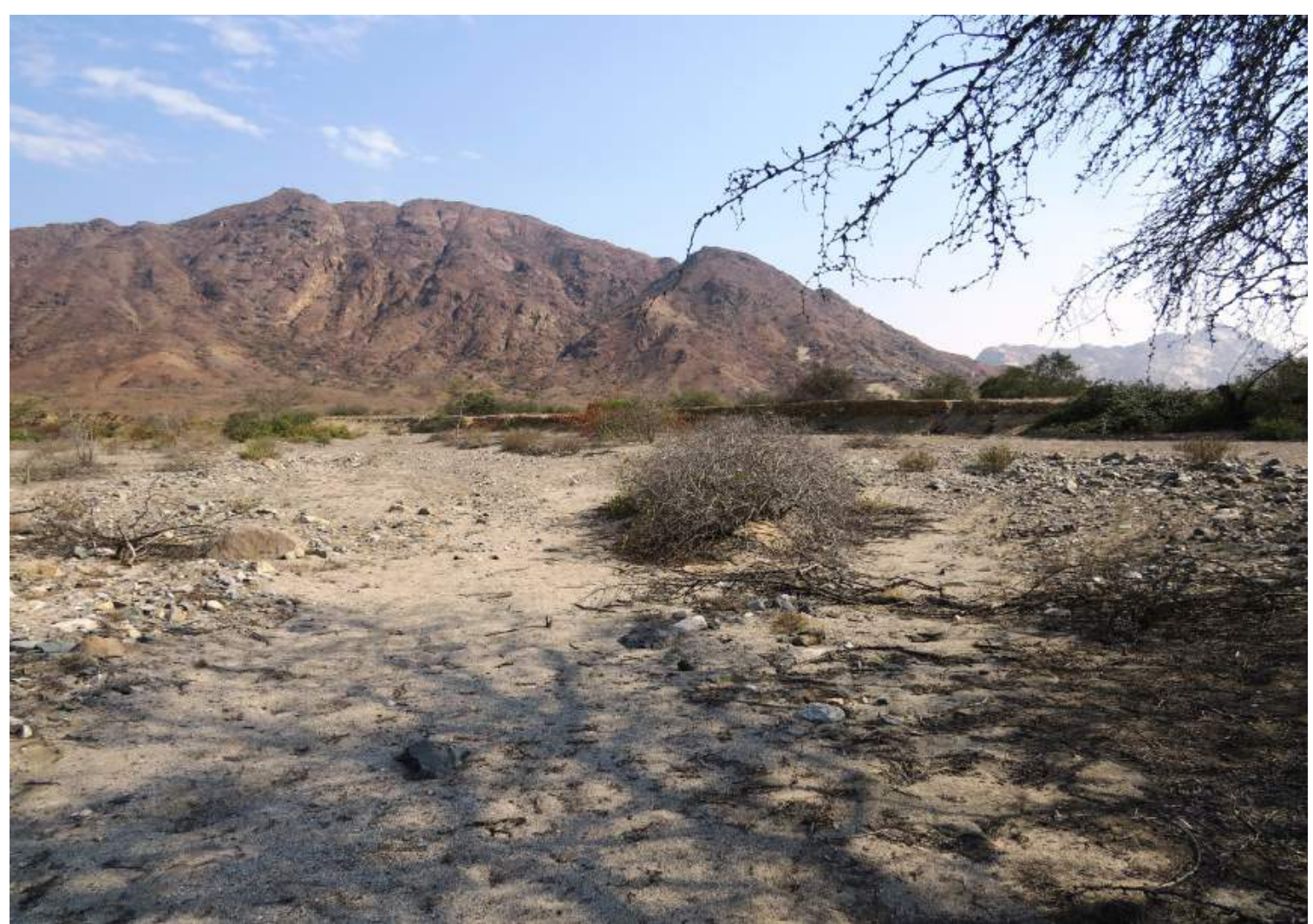

Figura 3 Río seco de la cuenca baja del Zaña, a cuyas se orillas se ubican el edificio y los petroglifos. 


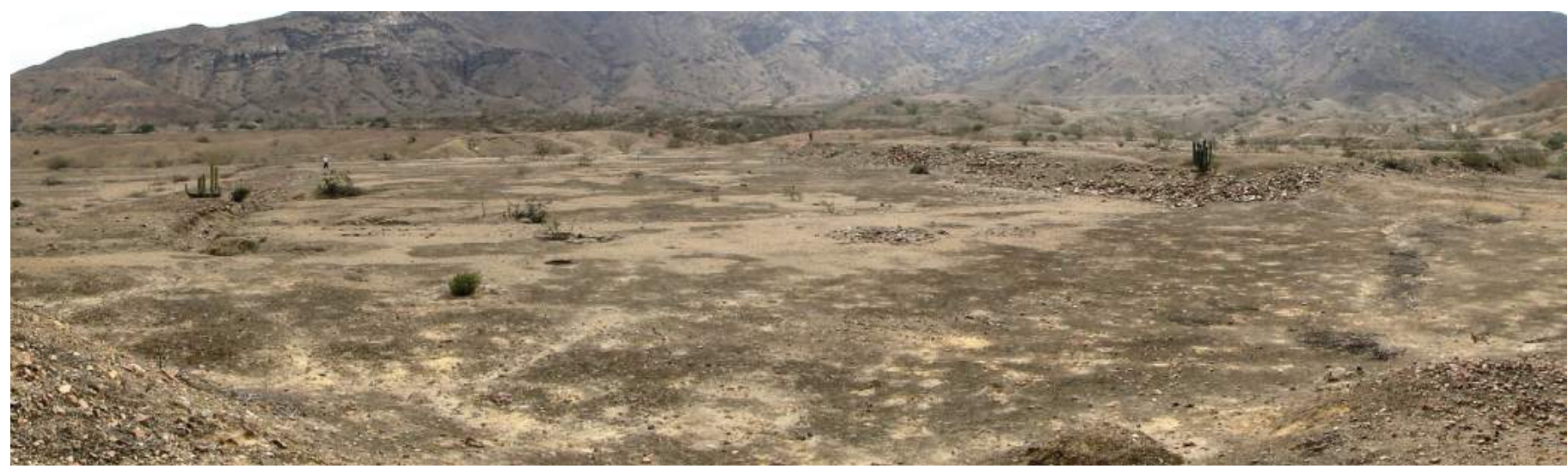

Figura 4 Templo de la Boa, edificio principal construido con lajas de piedra en un área de 10 mil metros cuadrados.

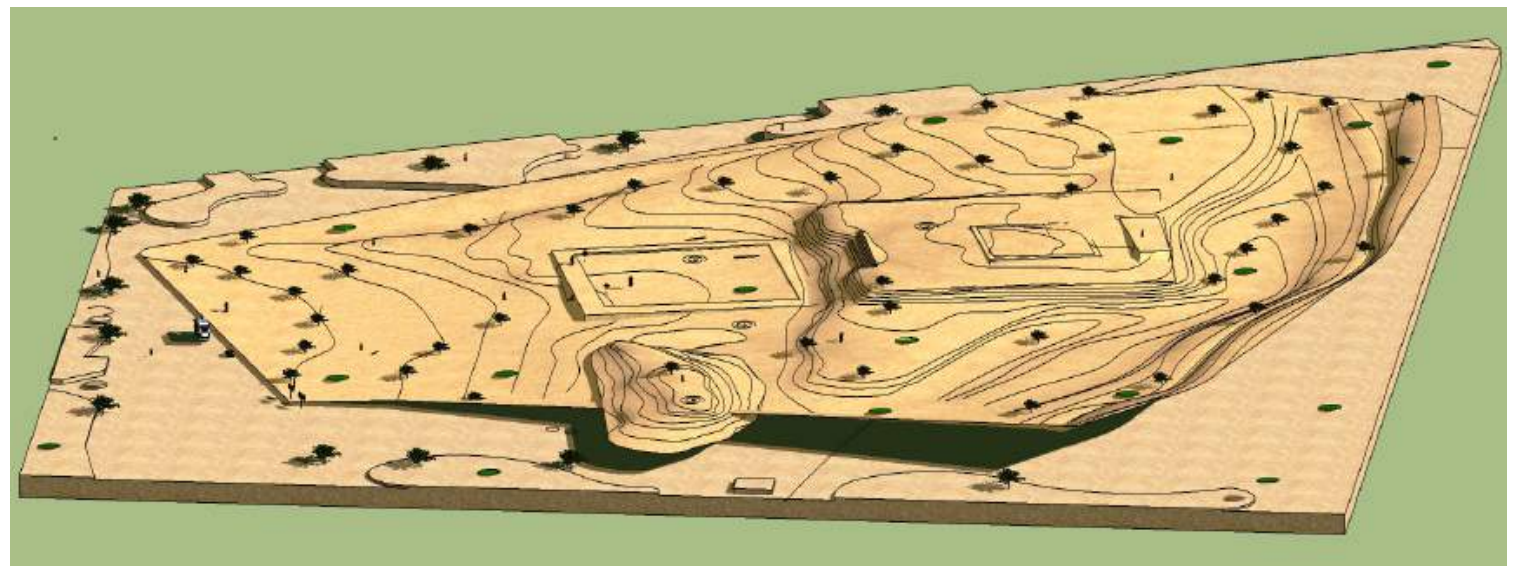

Figura 5 Levantamiento en 3D del edificio

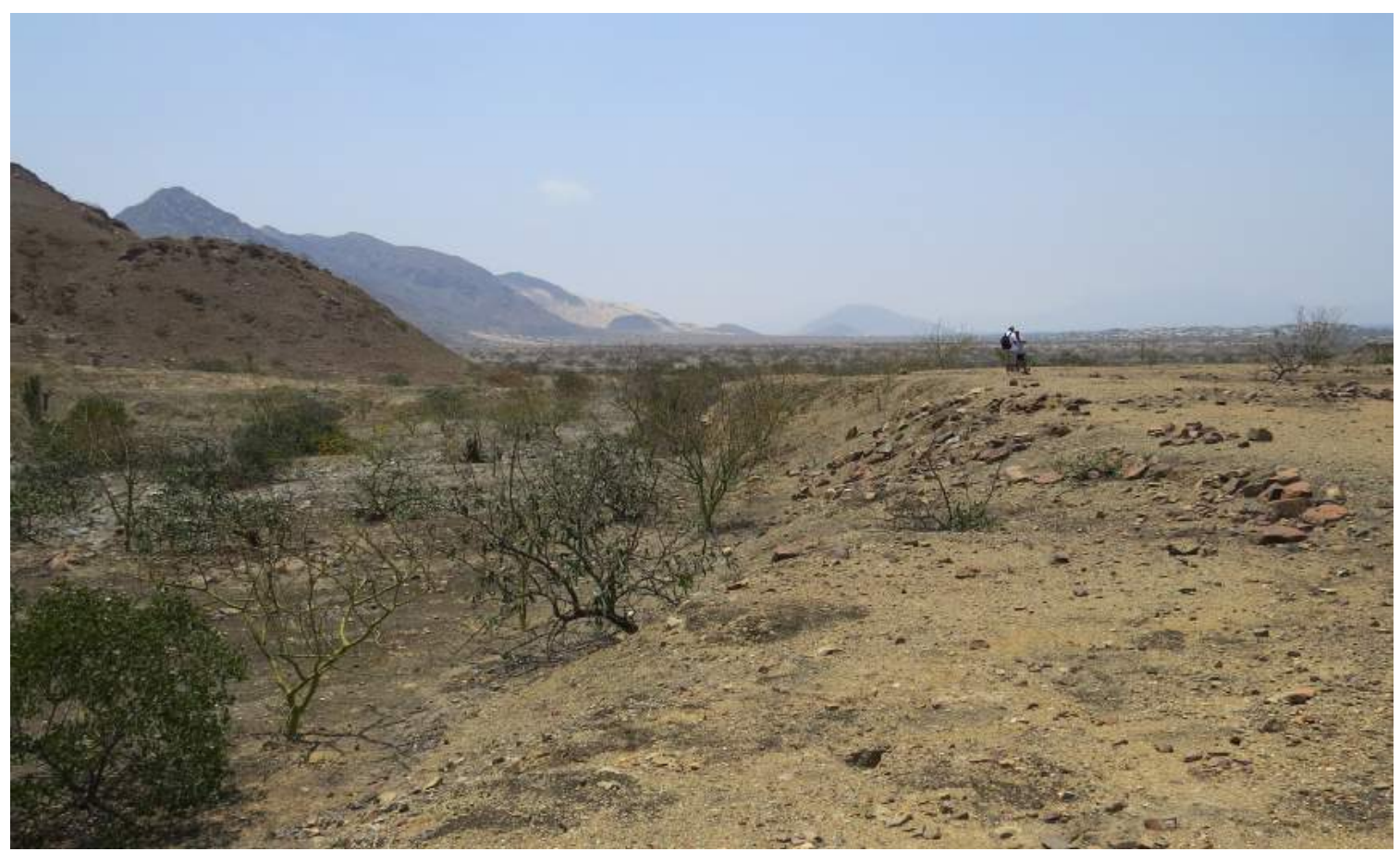

Figura 6 Vista posterior del edificio. Muro de contención a orillas del cauce. 


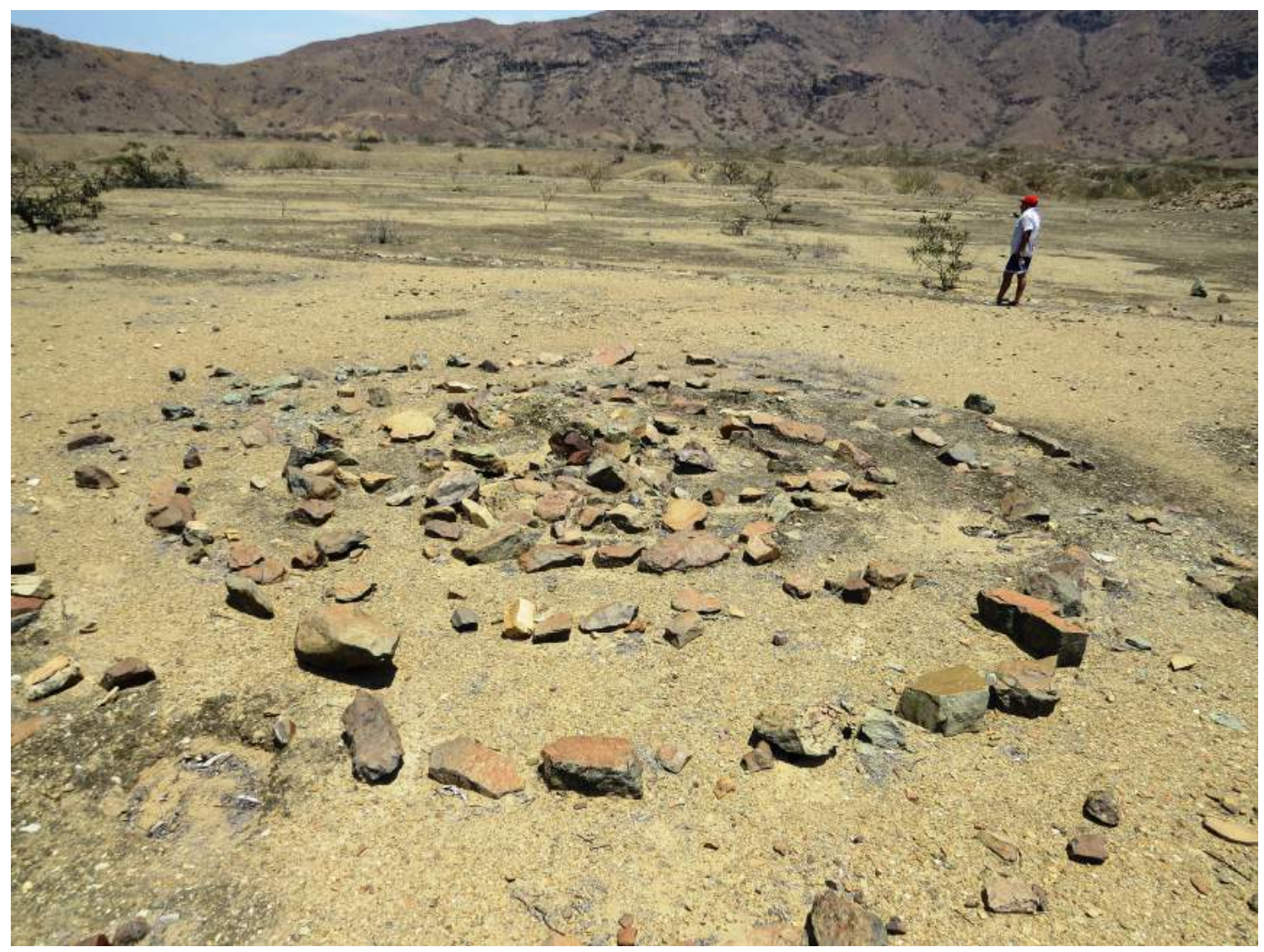

Figura 7 Espiral en la primera plataforma del edificio.

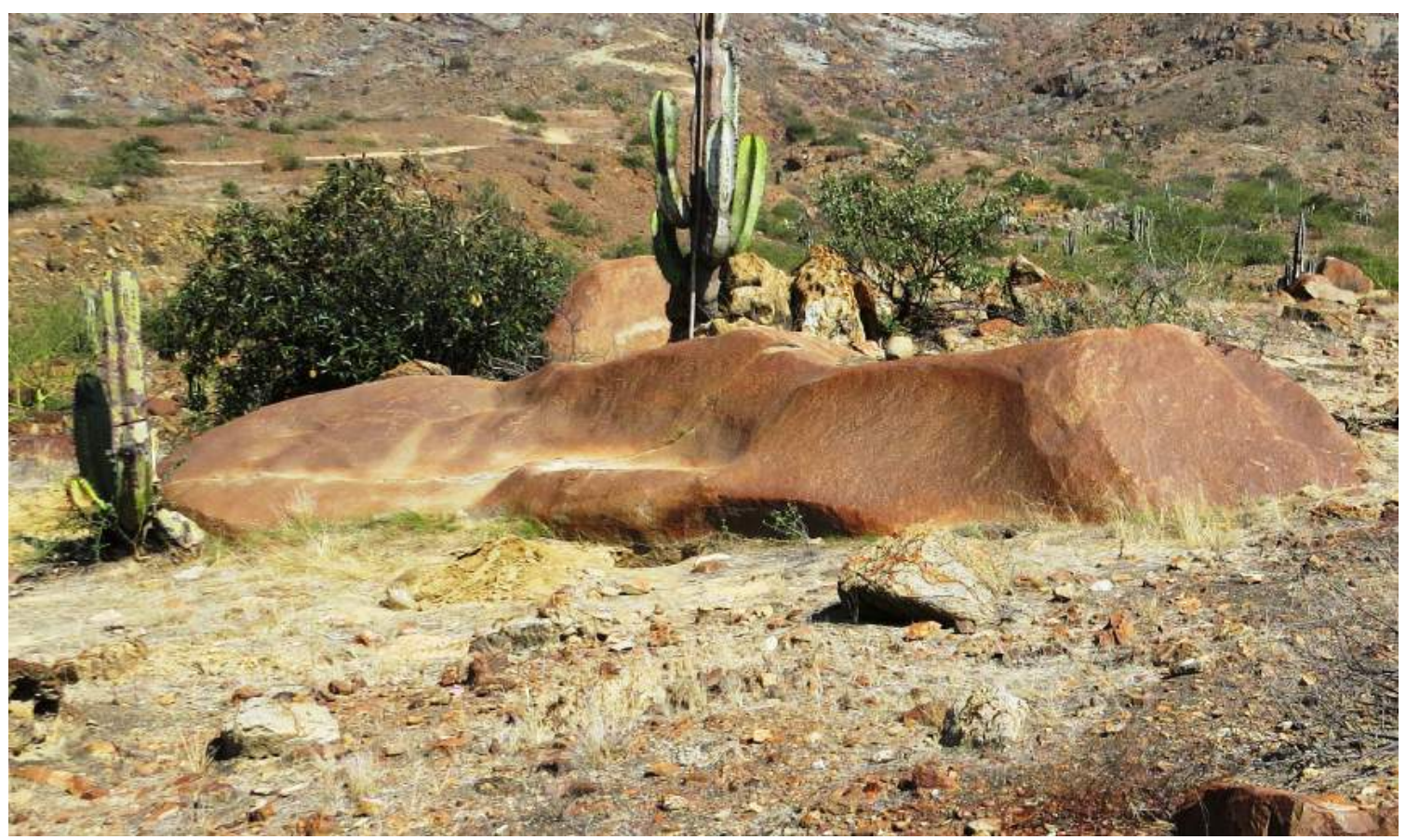

Figura 8 Piedra solitaria con petroglifos pre y chavín 


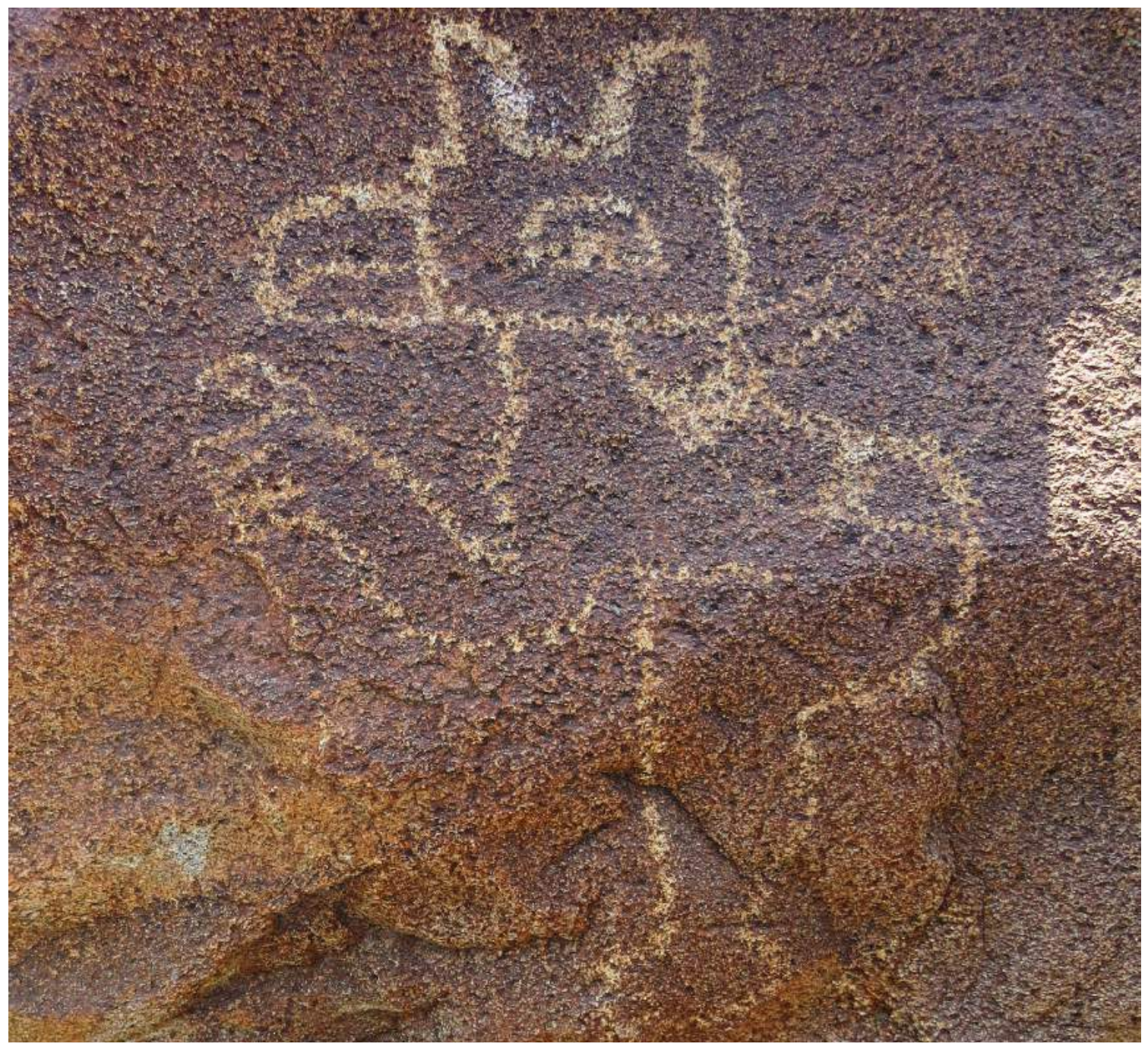

Figura 9 Petroglifo antropomorfo chavín

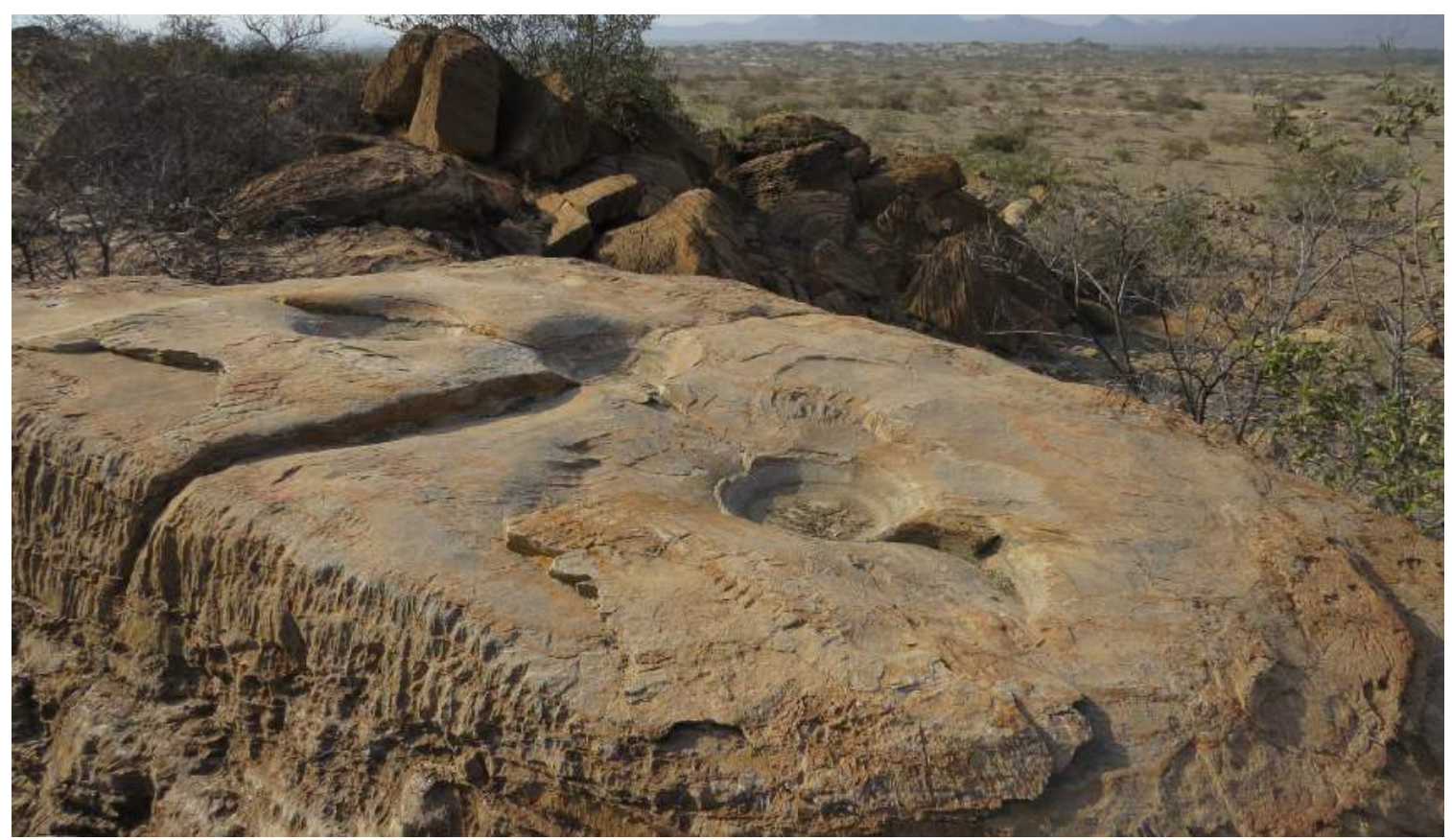

Figura 10 La piedra solitaria de los Cinco Huecos. 


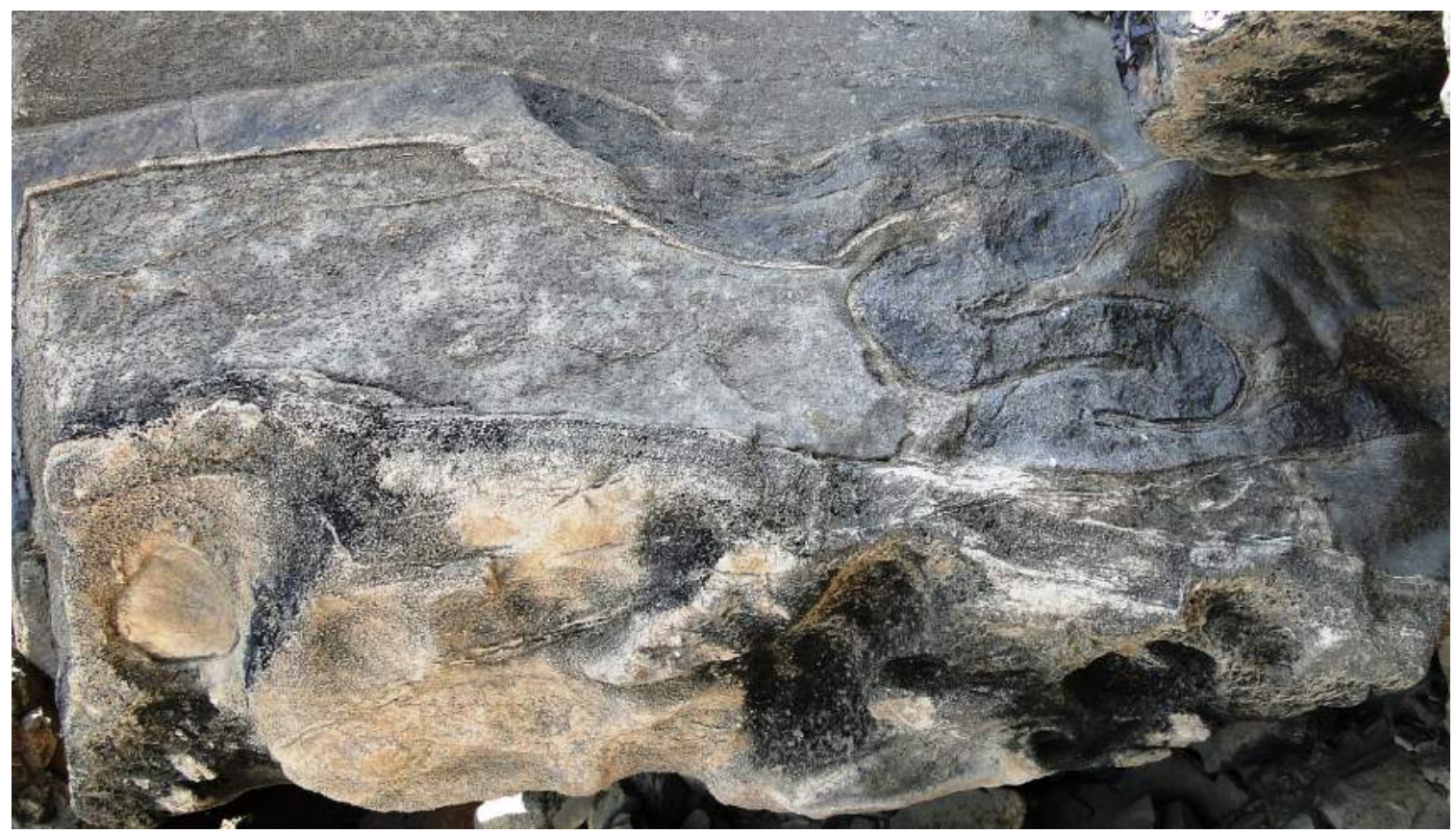

Figura 11 Las dos boas entrelazadas, en plano relieve, aprovechando la estratigrafía natural de la roca.

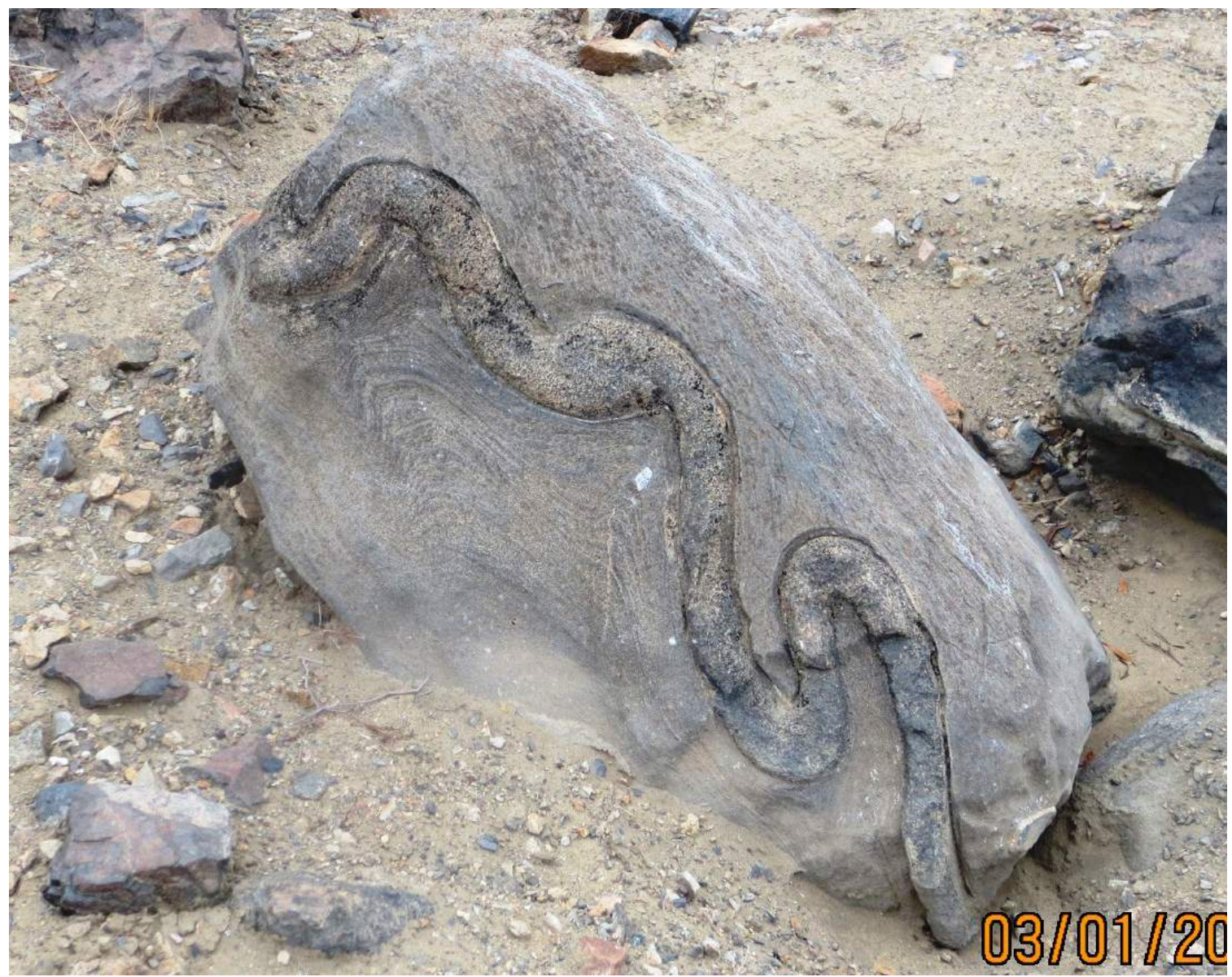

Figura 12 El tótem de las boas en alto relieve 


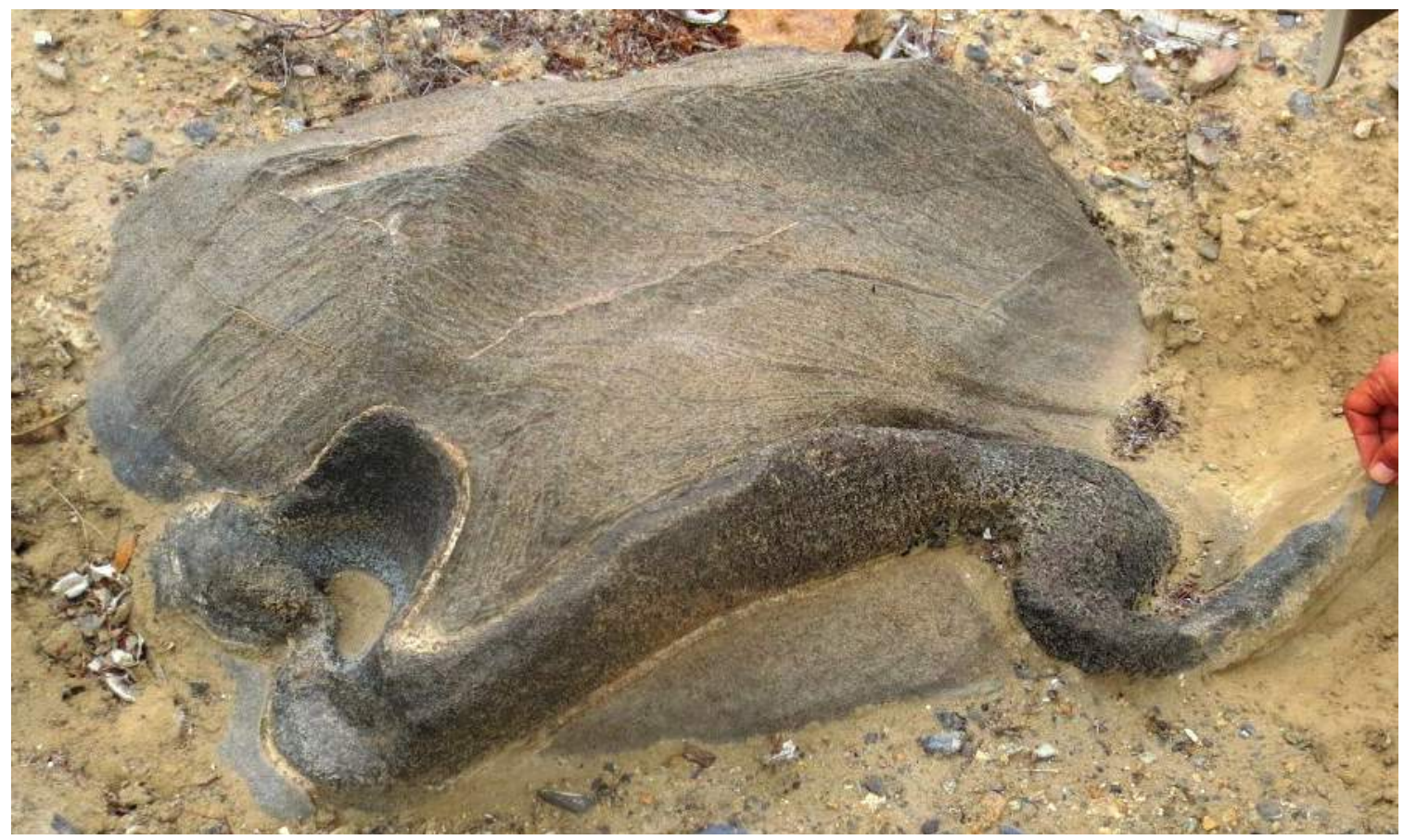

Figura 13 Una segunda piedra con la figura de la boa en alto relieve.

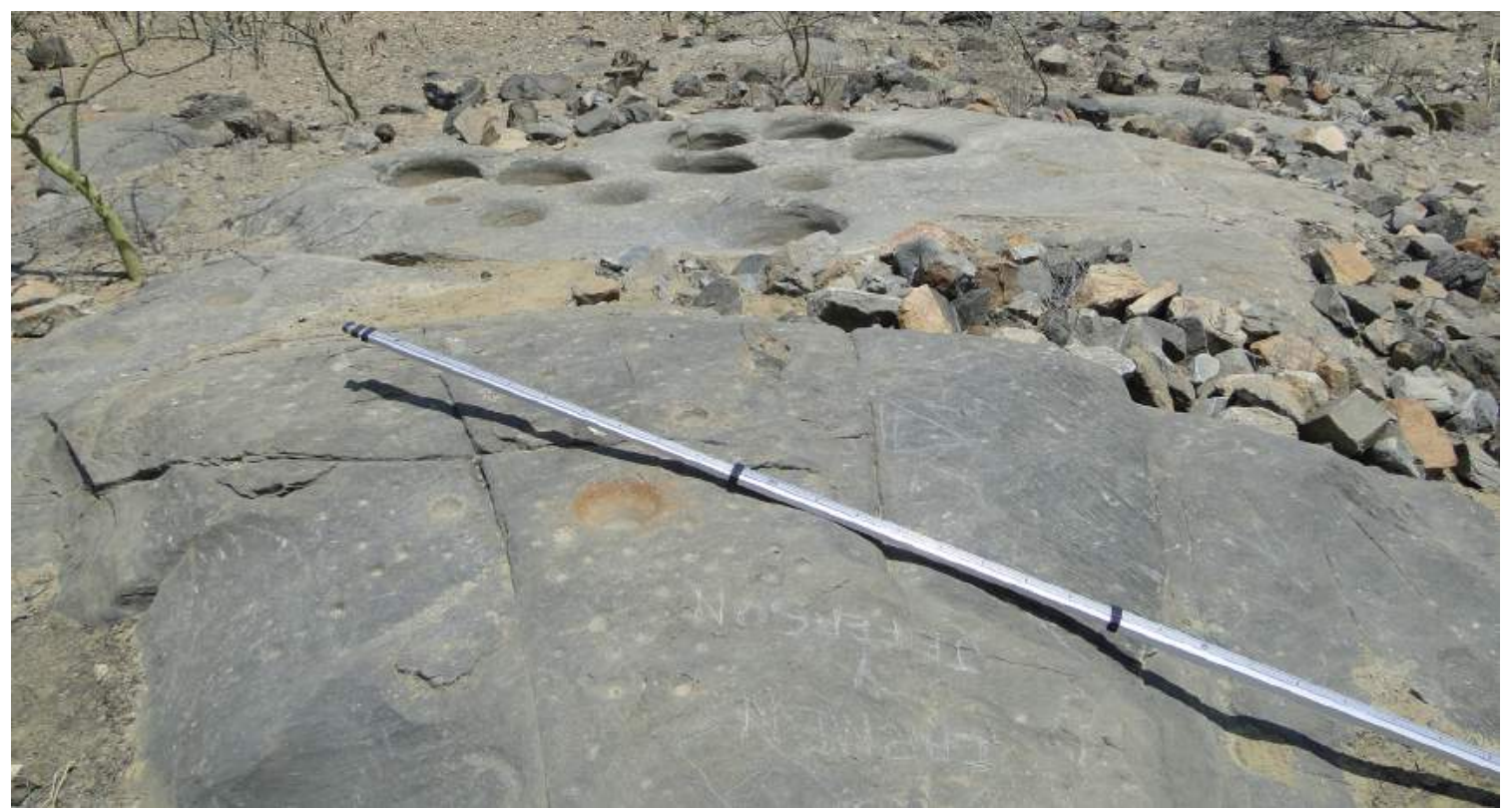

Figura 14 "Las Tinajas" y los hoyos cónicos asociados a los petroglifos. 


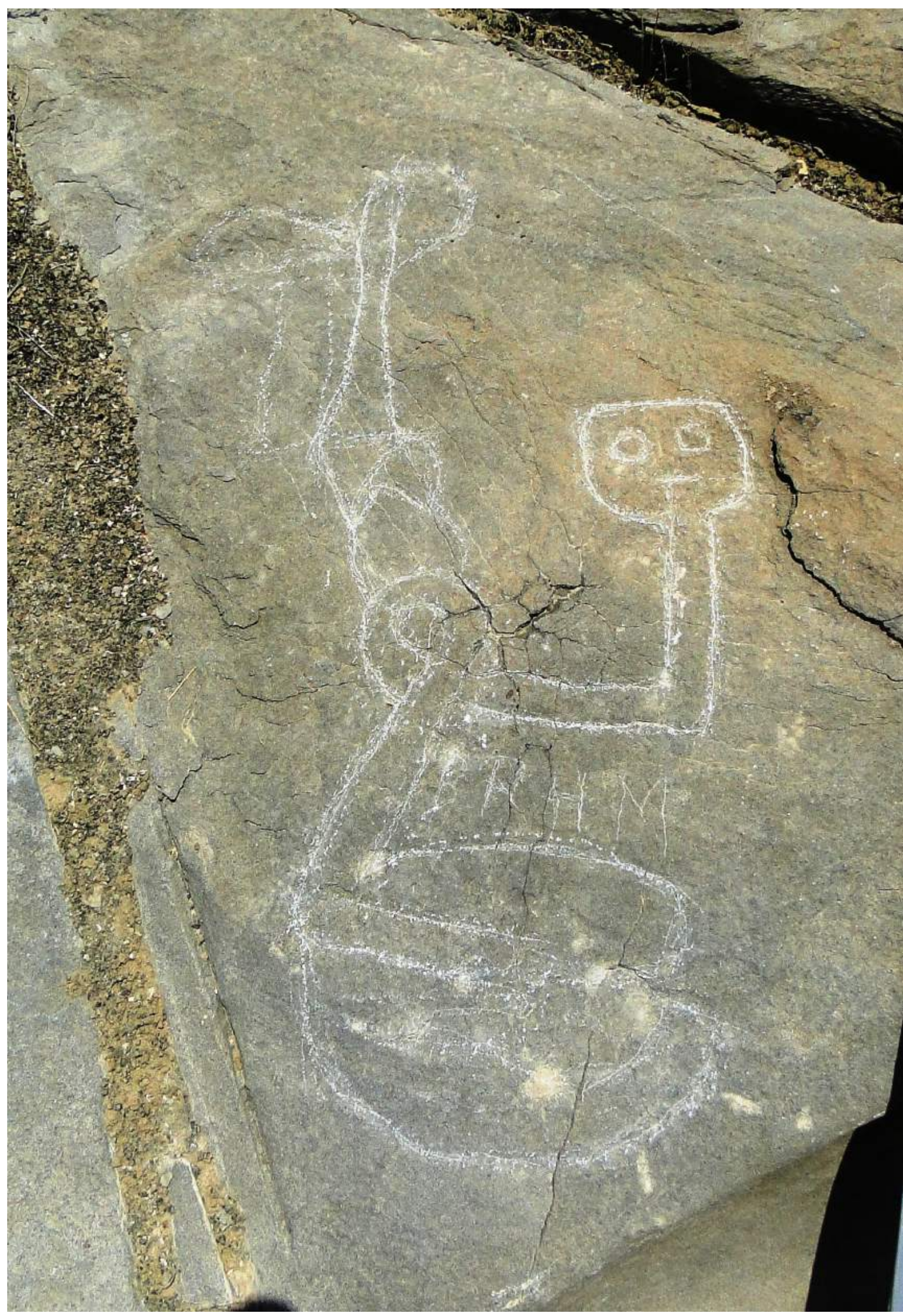

Figura 15 Petroglifo de la boa. 


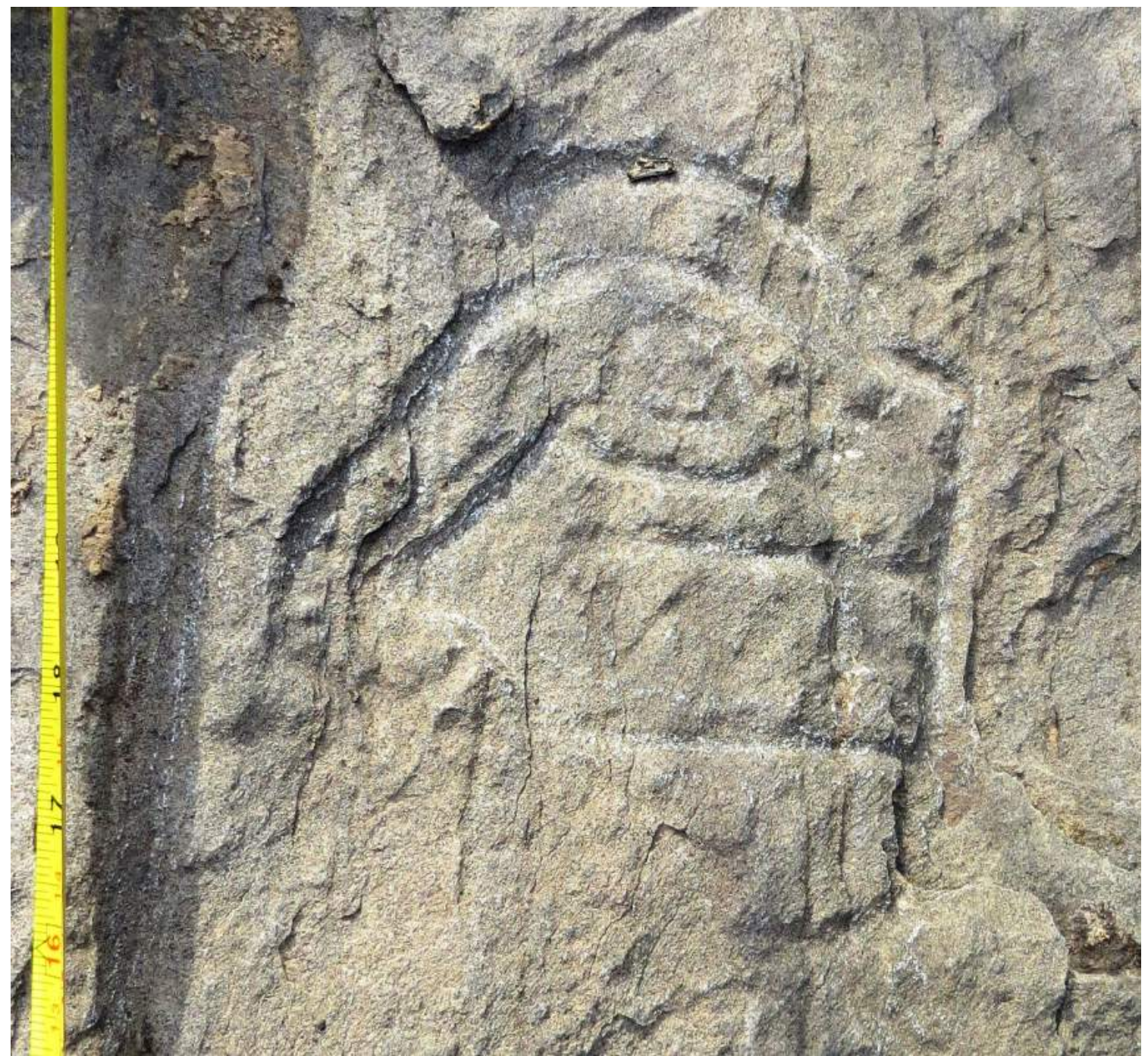

Figura 16 Petroglifo rostro humano. Cultura Chavín



Figura 17 El felino, nótese el gran parecido con la figura del felino en el Templo de Sechín, Casma. 


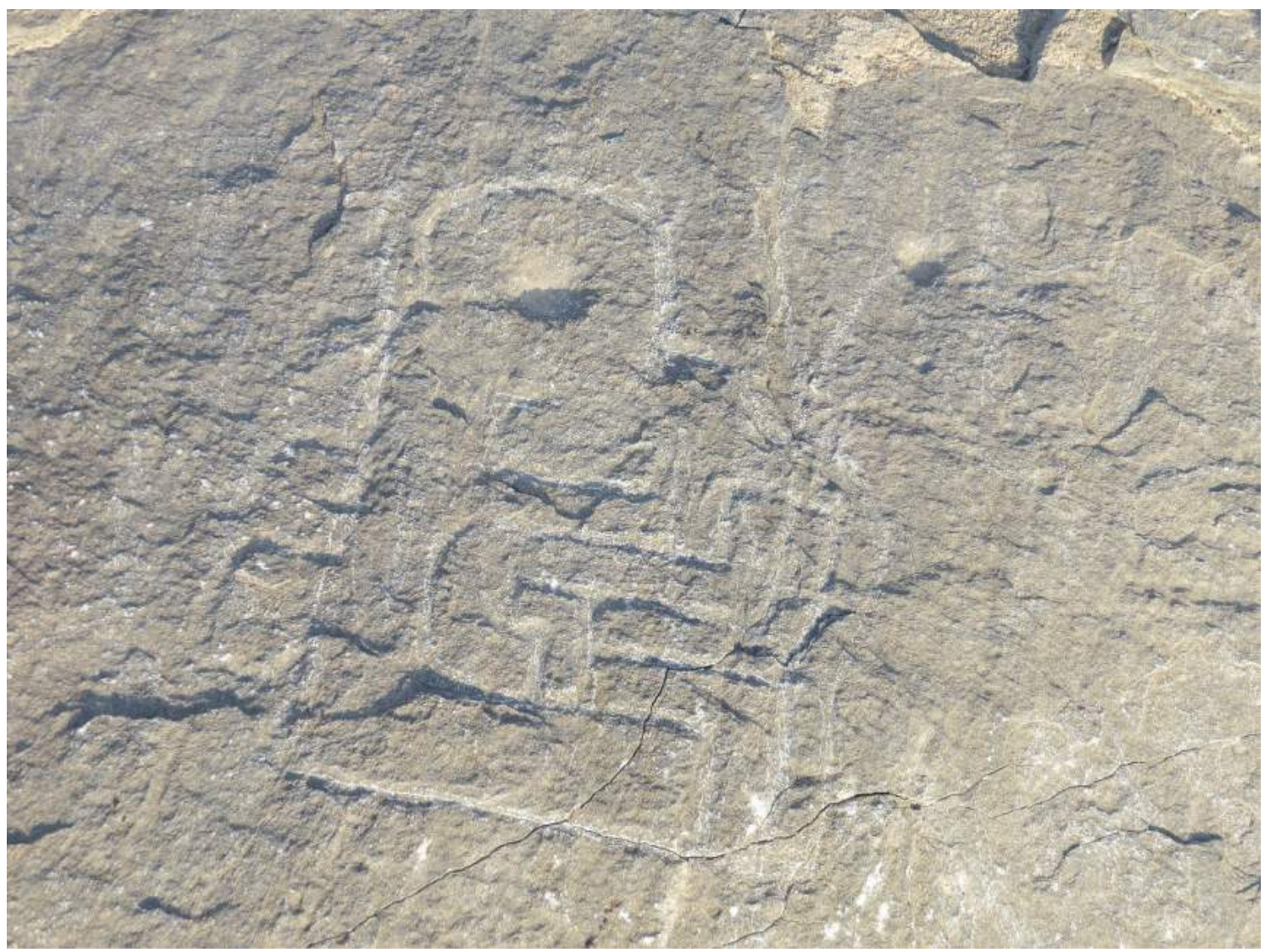

Figura 18 Rostro humano. Cultura Chavín



Figura 19 Geoglifo de la boa 


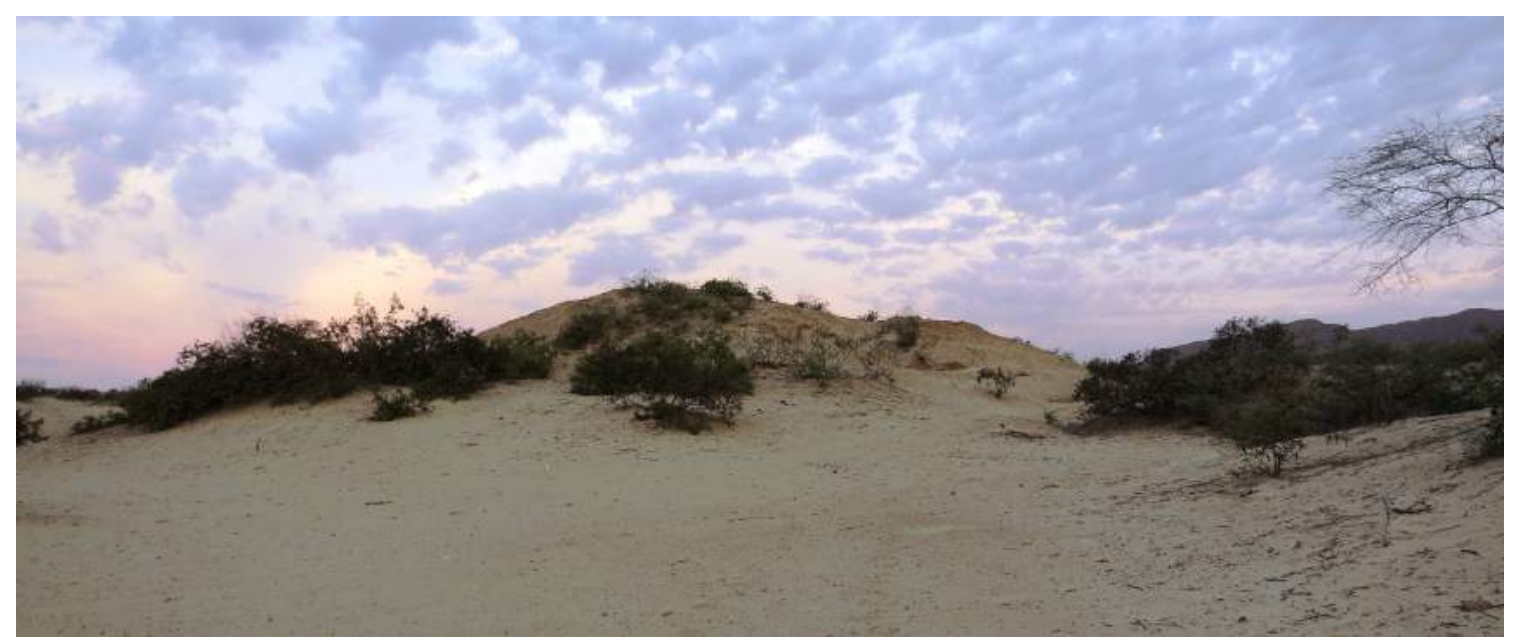

Figura 20 El edificio chavín: "Huaca de la Ternera."

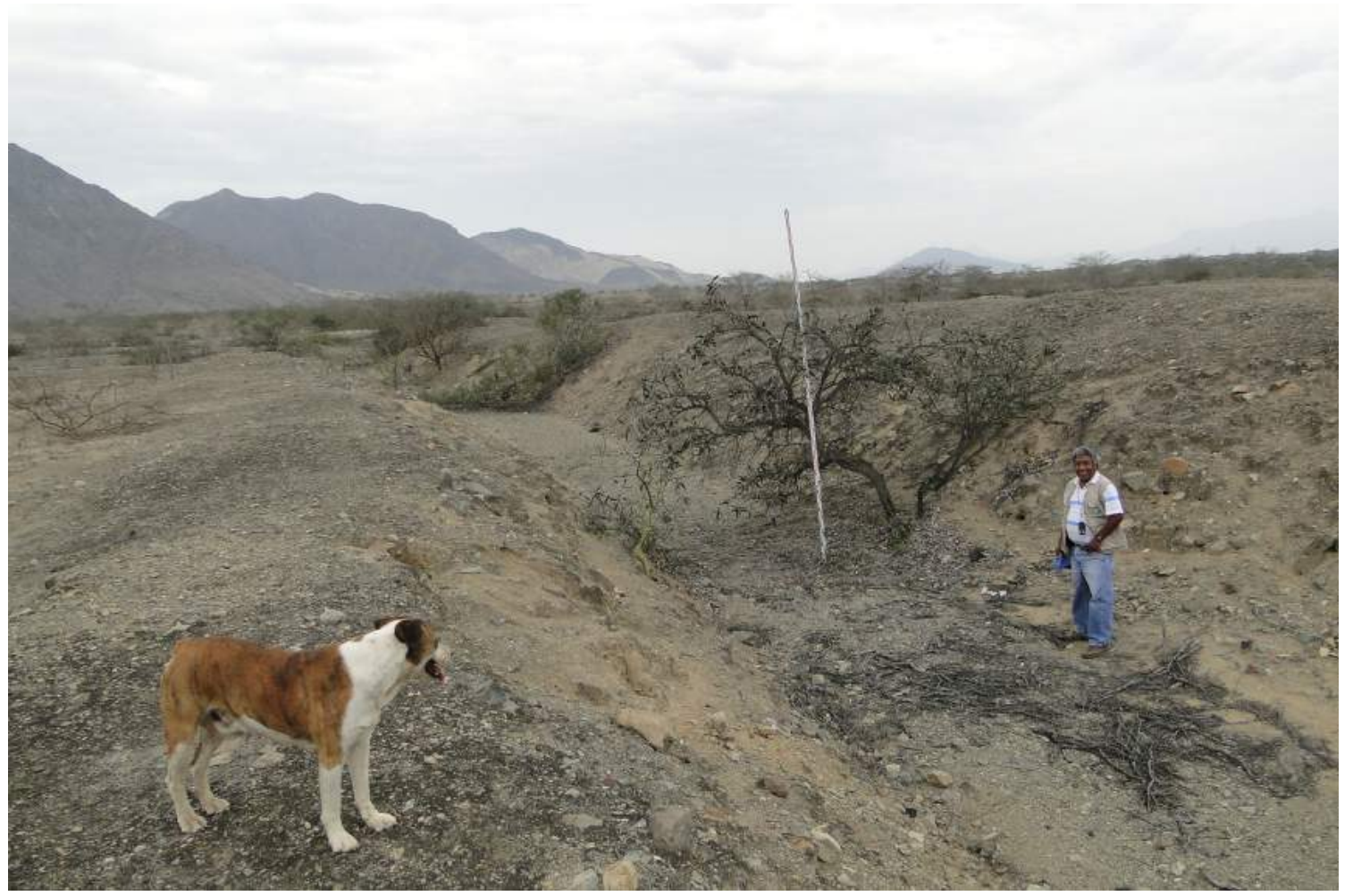

Figura 21 Canal de riego siglo X de nuestra era que viene desde Nanchoc y se dirige a Saltrapón y pampas de Lagunas 


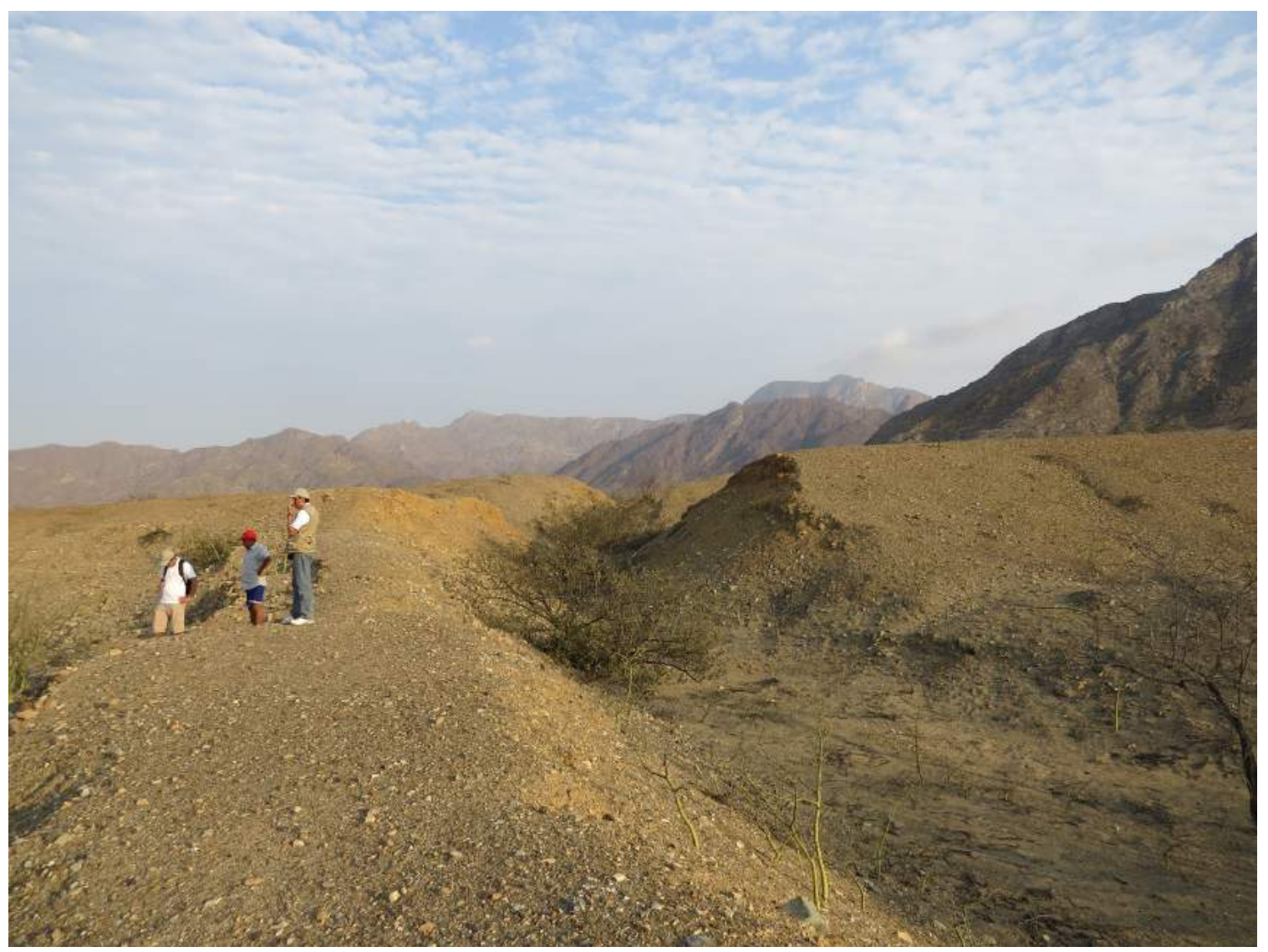

Figura 22 Canal de riego siglo X de nuestra era que viene desde Nanchoc y se dirige a Saltrapón y pampas de Lagunas

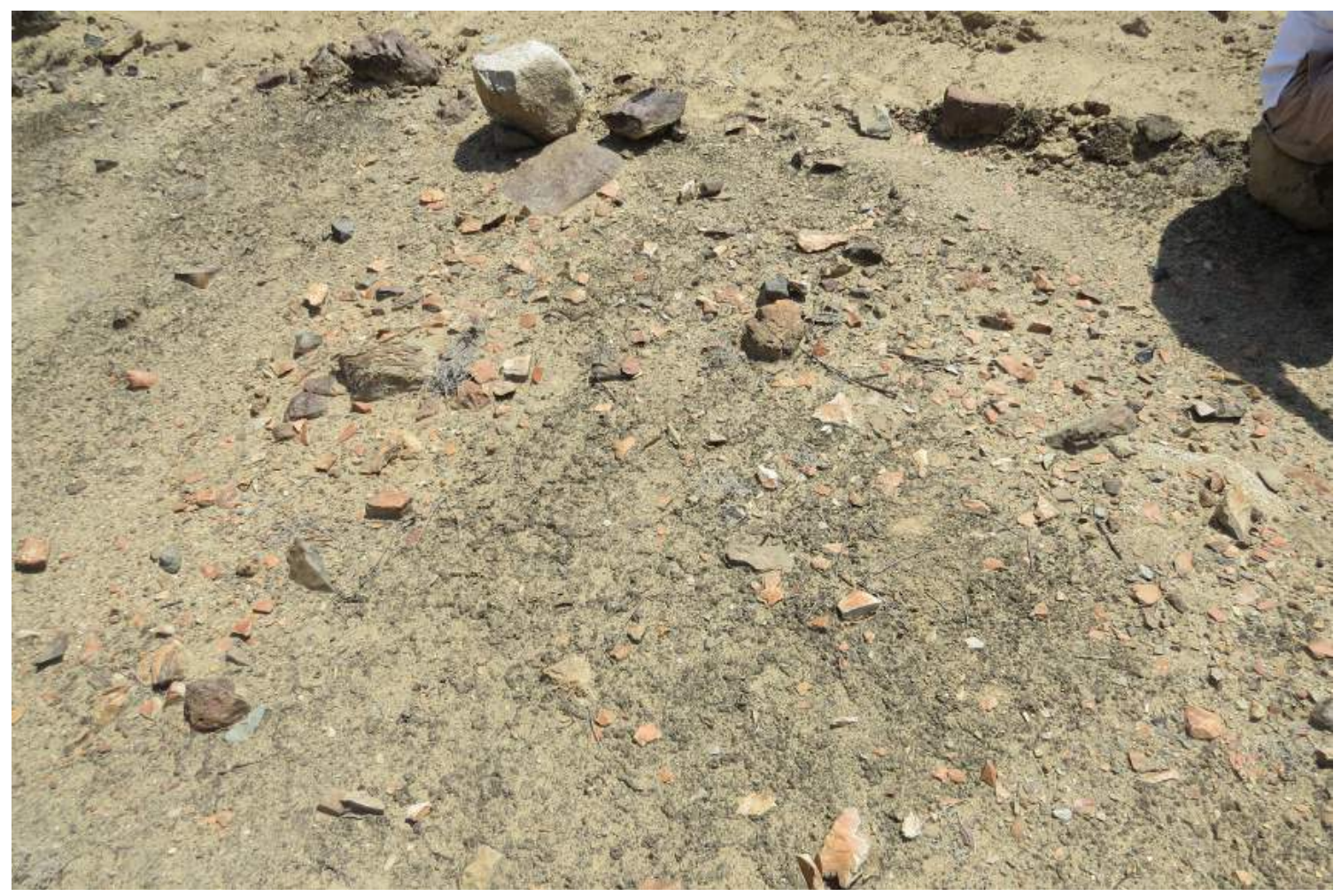

Figura 23 Taller Lítico 